\title{
Digestibilidade e Absorção Aparentes em Vacas da Raça Holandesa Alimentadas com Palma Forrageira (Opuntia ficus-indica Mill) em Substituição à Silagem de Sorgo (Sorghum bicolor (L.) Moench) ${ }^{1}$
}

\section{Dulciene Karla Bezerra de Andrade ${ }^{2}$, Marcelo de Andrade Ferreira ${ }^{3}$, Antonia Sherlânea Chaves Véras ${ }^{3}$, Walmir Lima Wanderley ${ }^{2}$, Luís Evandro da Silva ${ }^{4}$, Francisco Fernando Ramos de Carvalho ${ }^{3}$, Kaliandra Souza Alves ${ }^{2}$, Wellington Samay de Melo ${ }^{6}$}

\begin{abstract}
RESUMO - Foi avaliado o efeito de quatro níveis $(0,12,24$ e 36\%) de palma forrageira em substituição à silagem de sorgo, na ração de vacas da raça holandesa em lactação, sobre a digestibilidade aparente da matéria seca (DAMS), da matéria orgânica (DAMO), da proteína bruta (DAPB), do extrato etéreo (DAEE), da fibra em detergente neutro (DAFDN), da fibra em detergente ácido (DAFDA), dos carboidratos totais (DACHT) e dos carboidratos não-fibrosos (DACNF), o teor de nutrientes digestíveis totais (NDT) e os coeficientes de absorção aparente de cálcio $(\mathrm{Ca})$, fósforo $(\mathrm{P})$, potássio $(\mathrm{K})$ e sódio $(\mathrm{Na})$. Foram utilizadas oito vacas, com peso médio de $590 \mathrm{~kg}$ e produção média de leite de $27 \mathrm{~kg} /$ dia, distribuídas em dois quadrados latinos simultâneos $(4 \mathrm{x} 4)$, sendo quatro animais, quatro períodos e quatro níveis de inclusão de palma na ração. A inclusão de palma forrageira na dieta influenciou a digestibilidade aparente de todos os nutrientes, sendo descrito por função quadrática. Foi possível estimar por intermédio desta função um teor máximo de NDT de 77,43\% para utilização de 16,51\% de palma na dieta. O aumento nos teores de CNF e a redução da FDN das rações foram responsáveis pelo comportamento quadrático na digestibilidade dos nutrientes. As absorções aparentes de $\mathrm{Ca}, \mathrm{P}$ e Na foram influenciadas quadraticamente com o aumento dos níveis de palma na ração, enquanto o K aumentou linearmente. A relação Ca:P que proporcionou a melhor absorção desses elementos minerais foi de 1,9:1.
\end{abstract}

Palavras-chave: carboidratos não-fibrosos, fibra em detergente neutro, matéria seca, mineral

\section{Apparent Digestibility and Absorption od Holstein Cows Fed Diets with Forage Cactus (Opuntia ficus-indica Mill) in Replacement of Sorghum silage (Sorghum bicolor (L.) Moench)}

\begin{abstract}
It was evaluated the effect of four levels forage cactus in replacement of sorghum silage, in diets of lactating Holstein cows, on the apparent digestibility of dry matter (ADDM), organic matter (ADOM), crude protein (ADCP), ether extract (ADEE), neutral detergent fiber (ADNDF) and acid (ADADF), total carbohydrates (ADTCH) and nonfiber carbohydrates (ADNFC), content of total digestible nutrients (TDN) and apparent absorption of calcium (Ca), phosphorus (P), potassium (K) and sodium (Na). Eight Holstein cows averaging $590 \mathrm{~kg}$ and producing $27 \mathrm{~kg}$ of milk/day were used in a $4 \times 4$ Latin square design with four animals, four periods and four levels of forage cactus inclusion. All nutrients apparent digestibility showed significant quadratic response with increasing cactus in diets. Significant quadratic responses of apparent digestibility would likely attributed to increase in amounts NFC, decrease NDF and $\mathrm{ADF}$ in diets. The apparent absorption for $\mathrm{Ca}, \mathrm{P}$ and $\mathrm{Na}$ also showed significant quadratic response. However, $\mathrm{K}$ had linear increase. The Ca:P ratio that provided better apparent absorption for the two mineral elements was 1.9:1.
\end{abstract}

Key Words: dry matter, mineral, neutral detergent fiber, nonfiber carbohydrates

\section{Introdução}

A bovinocultura leiteira tem importante papel sócio-econômico-cultural para a região Nordeste do Brasil. Contudo, apesar de amplos recursos naturais, a baixa produtividade de seu rebanho é, em parte, reflexo das carências nutricionais a que está submetido.
Este fato está associado ao alto custo das dietas e à baixa disponibilidade de forragens, em função da irregularidade das chuvas, do manejo e aproveitamento inadequado das pastagens.

Face a essas condições, a consolidação da exploração bovina, no agreste e no sertão de Pernambuco, tem como base a utilização da palma forrageira

\footnotetext{
${ }^{1}$ Parte da tese apresentada à UFRPE para obtenção do título Magister Scientiae.

2 Aluno de Pós-Graduação em Zootecnia da UFRPE.

3 Professor do curso de Zootecnia da UFRPE. E.mail: mcelo@yahoo.com

4 Pesquisador do IPA.

${ }^{5}$ Bolsista do CNPq.

${ }^{6}$ Aluno de Graduação em Zootecnia/UFRPE.
} 
(Opuntia sp. e Nopalea cochonillifera Salm Dyck), que, devido às suas características morfofisiológicas, tolera bem longas estiagens (Santos et al., 1997). A presença de palma forrageira na dieta supre em grande parte as necessidades de água dos animais, sendo, muitas vezes, o único alimento disponível na época seca (Farias et al., 1984; Lima et al., 1985).

Segundo Santos et al. (1990) e Wanderley et al. (2002), esta cactácea é um alimento suculento, rico em água e mucilagem, com significativos teores de minerais, principalmente cálcio $(\mathrm{Ca})$, potássio $(\mathrm{K})$ e magnésio $(\mathrm{Mg})$. Apresenta altos teores de carboidratos nãofibrosos (CNF) e elevado coeficiente de digestibilidade da matéria seca (MS). Por outro lado, possui baixos teores de MS (10 a 14\%), proteína bruta (4,0 a 6,0\%) e fibra em detergente neutro (26,8\%). Estas características podem causar perda de peso, depressão na produção e no teor de gordura do leite, bem como distúrbios digestivos (diarréias e ruminação pobre), como observado por Santana et al. (1972) e Santos et al. (1990).

Como alternativa, sua associação a fontes de fibra aumenta o teor de MS da dieta e mantém o rúmen em condições normais, diminuindo os efeitos indesejáveis da sua utilização como alimento único na dieta de vacas em lactação (Lima et al., 1985; Oliveira, 1996; Mattos, 2000; Wanderley et al., 2002). Nesse sentido, o sorgo forrageiro tem se mostrado promissor, por sua tolerância ao déficit hídrico, capacidade de rebrota e boa composição química, contribuindo para o melhor equilíbrio nutricional das dietas (Schmidt, 1987).

O valor nutritivo de um alimento é determinado por interações entre os nutrientes e os microrganismos do rúmen, nos processos de digestão, absorção, transporte e utilização de metabólitos (Martins et al., 2000). Grande parte dessas informações é obtida por meio de estudos de digestibilidade (Rodrigues, 1998). Vários fatores podem influenciar a digestão dos alimentos, como composição dos alimentos e das dietas, efeito associativo entre alimentos, preparo e forma de arraçoamento, taxa de degradabilidade, relação proteína:energia e fatores inerentes ao animal (Van Soest, 1994; Ørskov, 2000).

Os carboidratos solúveis são fontes importantes de energia utilizada para atender às exigências de vacas de altas produções (Valadares Filho, 2000). Contudo, altos teores desses compostos podem comprometer a digestibilidade dos nutrientes e causar distúrbios metabólicos, devido ao abaixamento do pH ruminal e aumento na taxa de passagem, diminuindo a atividade celulolítica e, conseqüentemente, a digestibilidade da fibra (Van Soest, 1994; Rodrigues, 1998; Ørskov, 2000).

Além desses fatores, a digestão do alimento depende da adequada nutrição mineral dos microrganismos ruminais (McDowell, 2001). Dessa forma, além dos demais nutrientes, os ruminantes devem receber, durante todo o seu ciclo de vida, macro e micro elementos inorgânicos em quantidades e proporções adequadas. Isto pode ser alcançado a partir do conhecimento da biodisponibilidade desses minerais, para garantir os processos vitais e otimizar a saúde e a desempenho animal (Signoretti et al., 1999).

A palma forrageira apresenta elevados teores de Ca $(3,74), \mathrm{K}(1,83)$ e Mg $(2,14) \%$ na MS (Santos, 1989; Germano et al., 1991). Estes valores estão acima das exigências estabelecidas pelo NRC (1989) para vacas em lactação, com peso vivo de $600 \mathrm{~kg}$ e produção diária de $30 \mathrm{~kg}$. Isto pode limitar a absorção desses minerais, prejudicando o crescimento da microbiota ruminal e a digestibilidade dos nutrientes (Ben Salem et al., 1996).

Os teores de $\mathrm{P}$ na palma forrageira, como na maioria das forragens, são considerados baixos $(0,08$ - 0,16), não fornecendo quantidades suficientes para atender aos requerimentos dos animais (Santos, 1989; Germano et al., 1991; Cunha, 1996). Este fato é importante, visto que a deficiência de $\mathrm{P}$ pode determinar efeito negativo sobre o consumo e também sobre a digestibilidade dos nutrientes (McDowell, 1996, Carvalho, 1998).

Neste estudo foram determinados os efeitos da substituição da silagem de sorgo por palma forrageira, sobre os coeficientes de DAMS, DAMO, DAPB, DAEE, DAFDN, DAFDA, DACHT e DACNF, o teor de NDT e os coeficientes de absorção aparente de $\mathrm{Ca}, \mathrm{P}, \mathrm{K}$ e Na, em vacas holandesas em lactação.

\section{Material e Métodos}

O experimento foi realizado na Estação Experimental da Empresa Pernambucana de Pesquisa Agropecuária (IPA), localizada na cidade de São Bento do Una - PE. Foram utilizadas oito vacas da raça Holandesa, variedade preta e branca, com peso vivo (PV) médio de $590 \mathrm{~kg}$ e produção média diária de leite de $27 \mathrm{~kg}$. Os animais entraram no período experimental logo após o pico de lactação.

O experimento teve duração de 84 dias, compostos por quatro períodos de 21 dias, sendo 14 dias para a adaptação dos animais às dietas experimentais e

R. Bras. Zootec., v.31, n.5, p.2088-2097, 2002 
sete dias para coleta. Os animais foram alojados, individualmente, em piquetes com cerca de arame farpado e piso de terra batida, tendo área coberta de $3 \mathrm{~m}^{2}$, provida de comedouro de madeira e área para livre acesso de $30 \mathrm{~m}^{2}$ com bebedouro de alvenaria. Nos horários de temperatura mais elevada (11 às 15h30), os animais permaneciam em um galpão de alvenaria, coberto com telhas de cerâmica.

A dieta foi formulada de acordo com as recomendações do NRC (1989), para atender as exigências de vacas em lactação com produção de leite de $30 \mathrm{~kg} / \mathrm{dia}$ com 3,5\% de gordura. A relação volumoso:concentrado foi de 57:43, sendo o volumoso constituído de palma forrageira associada à silagem de sorgo. A composição bromatológica dos ingredientes, a proporção dos ingredientes nas dietas e a composição bromatológica das dietas experimentais são apresentadas nas Tabelas 1, 2 e 3, respectivamente.

A dieta foi fornecida à vontade, na forma de mistura completa, duas vezes ao dia, com água à

Tabela 1 - Teores de matéria seca (MS), matéria orgânica (MO), proteína bruta (PB), extrato etéreo (EE), fibras em detergente neutro (FDN) e ácido (FDA), carboidratos totais (CHT), carboidratos não-fibrosos (CNF), cálcio $(\mathrm{Ca})$, fósforo $(\mathrm{P})$, potássio $(\mathrm{K})$ e sódio $(\mathrm{Na})$ da palma forrageira, silagem de sorgo e do concentrado

Table 1 - Contents of dry matter (DM), organic matter (OM), crude protein $(C P)$, ether extract (EE), neutral detergent fiber (NDF) and acid (ADF), total carbohydrates $(\mathrm{TCH})$, nonfiber carbohydrates (NFC), calcium (Ca), phosphorus $(P)$, potassium $(K)$ and sodium $(\mathrm{Na})$ of forage cactus, sorghum silage and concentrate

\begin{tabular}{|c|c|c|c|}
\hline \multirow[t]{2}{*}{ Itens } & \multicolumn{3}{|c|}{$\begin{array}{l}\text { Ingredientes } \\
\text { Ingredients }\end{array}$} \\
\hline & $\begin{array}{c}\text { Palma } \\
\text { forrageira } \\
\text { Forage cactus }\end{array}$ & $\begin{array}{c}\text { Silagem } \\
\text { de sorgo } \\
\text { Sorghum silage }\end{array}$ & $\begin{array}{l}\text { Concentrado } \\
\text { Concentrate }\end{array}$ \\
\hline $\operatorname{MS}(\%)^{2}(D M)$ & 12,63 & 30,53 & 88,37 \\
\hline $\mathrm{MO}^{1,2} \quad(O M)$ & 93,41 & 94,53 & 94,03 \\
\hline $\mathrm{PB}^{1,2} \quad(C P)$ & 4,45 & 8,75 & 31,29 \\
\hline $\mathrm{EE}^{1,2} \quad(E E)$ & 0,84 & 1,65 & 1,70 \\
\hline $\mathrm{FDN}^{1,2}(N D F)$ & 26,17 & 65,12 & 9,60 \\
\hline $\mathrm{FDA}^{1,2}(A D F)$ & 20,05 & 35,06 & 7,24 \\
\hline $\mathrm{CHT}^{1,2}(\mathrm{TCH})$ & 87,96 & 83,82 & 61,05 \\
\hline $\mathrm{CNF}^{1,2}(N F C)$ & 61,79 & 18,70 & 51,45 \\
\hline $\mathrm{Ca}^{1}$ & 2,00 & 0,20 & 0,80 \\
\hline $\mathrm{P}^{1,2}$ & 0,12 & 0,21 & 0,75 \\
\hline $\mathrm{K}^{1,2}$ & 2,37 & 1,37 & 1,41 \\
\hline $\mathrm{Na}^{1,2}$ & Traços (Trace) & 0,026 & 0,32 \\
\hline
\end{tabular}

$1 \% \mathrm{MS}$ (\% DM).

${ }^{2}$ Wanderley et al. (2002).

R. Bras. Zootec., v.31, n.5, p.2088-2097, 2002
Tabela 2 - Composição percentual dos ingredientes nos tratamentos experimentais, com base na matéria seca

Table 2 - Composition (\%) of the experimental diets, on dry matter basis

\begin{tabular}{|c|c|c|c|c|}
\hline \multirow[t]{2}{*}{$\begin{array}{l}\text { Ingredientes (\%) } \\
\text { Ingredients (\%) }\end{array}$} & \multicolumn{4}{|c|}{$\begin{array}{c}\text { Níveis de palma }(\%) \\
\text { Levels of forage cactus }(\%)\end{array}$} \\
\hline & 0 & 12 & 24 & 36 \\
\hline $\begin{array}{l}\text { Palma forrageira } \\
\text { Forage cactus }\end{array}$ & - & 12 & 24 & 36 \\
\hline $\begin{array}{l}\text { Silagem de sorgo } \\
\text { Sorghum silage }\end{array}$ & 57 & 45 & 33 & 21 \\
\hline $\begin{array}{l}\text { Concentrado } \\
\text { Concentrate }\end{array}$ & 43 & 43 & 43 & 43 \\
\hline
\end{tabular}

Tabela 3 - Teores de matéria seca (MS), matéria orgânica (MO), proteína bruta (PB), extrato etéreo (EE), fibra em detergente neutro (FDN) e ácido (FDA), carboidratos totais $(\mathrm{CHT})$, carboidratos não-fibrosos (CNF), cálcio $(\mathrm{Ca})$, fósforo $(\mathrm{P})$, potássio $(\mathrm{K})$ e sódio $(\mathrm{Na})$ das dietas experimentais

Table 3 - Contents of dry matter (DM), organic matter (OM), crude protein (CP), ether extract (EE), neutral detergent fiber (NDF) and acid (ADF), total carbohydrates (TCH), nonfiber carbohydrates (NFC), calcium $(\mathrm{Ca})$, phosphorus $(P)$, potassium $(K)$ and sodium $(\mathrm{Na})$ of the experimental diets

\begin{tabular}{|c|c|c|c|c|}
\hline \multirow[t]{2}{*}{ Item } & \multicolumn{4}{|c|}{$\begin{array}{c}\text { Níveis de palma }(\%) \\
\text { Levels of forage cactus }(\%)\end{array}$} \\
\hline & 0 & 12 & 24 & 36 \\
\hline $\operatorname{MS}(\%)^{2}(\mathrm{DM})$ & 55,40 & 53,25 & 51,10 & 48,95 \\
\hline $\mathrm{MO}^{1,2}(\mathrm{OM})$ & 94,31 & 94,18 & 94,04 & 93,91 \\
\hline $\mathrm{PB}^{1,2} \quad(\mathrm{CP})$ & 18,44 & 17,92 & 17,41 & 16,89 \\
\hline $\mathrm{EE}^{1,2}(\mathrm{EE})$ & 1,67 & 1,57 & 1,47 & 1,38 \\
\hline $\mathrm{FDN}^{1,2}(\mathrm{NDF})$ & 41,24 & 36,57 & 31,90 & 27,22 \\
\hline $\mathrm{FDA}^{1,2}(\mathrm{ADF})$ & 23,10 & 21,30 & 19,50 & 17,69 \\
\hline $\mathrm{CHT}^{1,2}(\mathrm{TCH})$ & 74,30 & 74,33 & 75,32 & 75,71 \\
\hline $\mathrm{CNF}^{1,2}(\mathrm{NFC})$ & 33,06 & 37,76 & 43,42 & 48,49 \\
\hline $\mathrm{Ca}^{1}$ & 0,46 & 0,67 & 0,89 & 1,10 \\
\hline $\mathrm{P}^{1,2}$ & 0,44 & 0,43 & 0,42 & 0,41 \\
\hline $\mathrm{K}^{1,2}$ & 1,39 & 1,50 & 1,63 & 1,75 \\
\hline $\mathrm{Na}^{1,2}$ & 0,15 & 0,15 & 0,14 & 0,14 \\
\hline $\mathrm{Ca}: \mathrm{P}$ & $1,05: 1$ & $1,56: 1$ & $2,12: 1$ & $2,68: 1$ \\
\hline
\end{tabular}

1\% MS (\% DM), ${ }^{2}$ Wanderley et al. (2002).

vontade. Diariamente, pela manhã, foram recolhidas e pesadas as sobras, tendo-se o cuidado de mantê-las em torno de 5 a $10 \%$ do fornecido, para garantir o consumo voluntário dos animais e a proporção dos ingredientes nas dietas.

Nos sete dias de coleta de cada período experimental, amostras de fezes foram retiradas diretamente na ampola retal dos animais, logo após as ordenhas da manhã e tarde. Nesses períodos, também foram 
coletadas, diariamente, amostras dos alimentos fornecidos e das sobras, sendo, em seguida, pré-secas em estufa com ventilação forçada a 55C, homogeneizadas, originando amostras compostas por período e por animal, e encaminhadas ao Laboratório de Nutrição Animal do Departamento de Zootecnia para posteriores análises.

As amostras compostas foram moídas em peneira com crivos de $1 \mathrm{~mm}$, das quaisse retiravam alíquotas representativas para a realização de análises de MS, PB, EE, FDA e cinzas, segundo metodologia proposta por Silva (1990), e FDN, segundo Van Soest et al (1991). As análises de Ca, P, K e Na, foram realizadas no Laboratório de Química Vegetal do Departamento de Química, conforme Bezerra Neto et al. (1994). Os teores de CHT e CNF foram calculados segundo Sniffen et al. (1992) e Mertens (1997), respectivamente, em que $\mathrm{CHT}=100-(\mathrm{PB}+\mathrm{EE}+$ Cinzas $)$ e $\mathrm{CNF}=$ $100-(\mathrm{FDN}+\mathrm{PB}+\mathrm{EE}+$ Cinzas $)$.

O consumo de NDT (CNDT), em quilogramas, e os teores de nutrientes digestíveis totais (NDT) foram calculados segundo Sniffen et al. (1992), pelas seguintes equações:

$\mathrm{CNDT}=(\mathrm{PB}$ ing. $-\mathrm{PB}$ fecal $)+2,25$ (EE ing. $-\mathrm{EE}$ fecal $)+($ CHT ing. - CHT fecal $)$ e NDT $(\%)=$ (Consumo de NDT / Consumo de MS) x 100

A estimativa da produção de matéria seca fecal (PMSF) foi obtida utilizando-se a fibra em detergente ácido indigestível (FDAi), como indicador interno (Berchielli et al., 2000), exceto quanto à incubação, que foi in situ. Amostras com cerca de $0,5 \mathrm{~g}$ de fezes, sobras e silagem e $1,0 \mathrm{~g}$ de palma e concentrado foram acondicionadas em sacos de ANKON e incubadas no rúmen de um bovino macho, adulto, por um período de 144 horas. O material remanescente da incubação foi levado ao Laboratório de Nutrição Animal do Departamento de Zootecnia lavado em água corrente e submetido à extração com detergente ácido, cujo resíduo foi considerado FDAi.

O delineamento experimental utilizado foi o quadrado latino $(4 \times 4)$, com quatro animais, quatro períodos e quatro níveis de inclusão de palma forrageira à dieta. Foram utilizados dois quadrados latinos simultâneos, um com vacas de segunda e outro com vacas de terceira lactação. Os dados foram submetidos à análise de variância e regressão utilizando-se o programa Sistema de Análises Estatísticas e Genéticas - Saeg (UFV, 1997). Os critérios utilizados para a escolha do modelo foram o coeficiente de determinação $\left(r^{2} / R^{2}\right)$, a significância observada por meio do teste t, em níveis de 1 e $5 \%$ de probabilidade, e o fenômeno biológico.

\section{Resultados e Discussão}

Na Tabela 4 são apresentadas as médias, os coeficientes de variação, as equações de regressão e os coeficientes de determinação $\left(R^{2}\right)$ das digestibilidades aparentes de matéria seca (DAMS), matéria orgânica (DAMO), proteína bruta (DAPB) e extrato etéreo (DAEE), observando-se comportamento quadrático para todas as variáveis, em função dos níveis de palma $(\mathrm{P})$ nas dietas experimentais.

Altos teores de carboidratos não-fibrosos (CNF) nas dietas, resultado da inclusão de palma (Tabela 3), foram, em parte, responsáveis pelo comportamento quadrático verificado para as DAMS, DAMO e dos outros nutrientes. Esses compostos são rapidamente digeridos, favorecendo a maior produção de ácidos graxos voláteis. A redução na fração de fibra em detergente neutro (FDN) resulta em menor salivação, sendo considerado um importante fator para diminuição do pH ruminal (Mertens, 2001), alterando a população microbiana, e diminui a digestibilidade dos nutrientes, evidenciando-se a importância do equilíbrio entre as concentrações de CNF e FDN da dieta.

Valadares Filho et al. (2000), trabalhando com níveis crescentes de concentrado na dieta de vacas em lactação, encontraram teores de CNF que variaram de 24,5 a $42,8 \%$ na MS da dieta. Segundo estes autores, geralmente ocorre aumento linear na DAMS, com redução do conteúdo menos digestível da FDN e aumento nos teores de CNF da dieta. Entretanto, vale salientar que os níveis de CNF nas dietas utilizadas por estes autores não ultrapassaram o limite de $43 \%$, sugerido pelo NRC (2001). Contudo, no presente trabalho, não foi verificado efeito linear para DAMS, DAMO, DAPB e DAEE, possivelmente devido ao fato de os teores de CNF terem sido mais elevados (33,06 a 48,49\%), conforme pode ser verificado na Tabela 3.

Carvalho et al. (1997) e Véras et al. (2000) descreveram comportamento semelhante para os coeficientes de DAMS e DAMO, ao utilizarem diferentes níveis de concentrado, chegando a 42,9 e $50,14 \%$ de carboidratos não-estruturais (CNE), respectivamente, na dieta de zebuínos não-castrados. A máxima digestibilidade desses nutrientes foi estimada em 59,80; 61,$70 ; 69,33$; e $70,75 \%$ para 42,$00 ; 40,50 ; 56,41$; e $56,69 \%$ de concentrado na dieta, respectivamente.

A relação entre a DAMS, os teores de CNF e

R. Bras. Zootec., v.31, n.5, p.2088-2097, 2002 
Tabela 4 - Médias, coeficientes de variação (CV), equações de regressão ajustadas (ER) e coeficientes de determinação $\left(R^{2}\right)$ das digestibilidades aparentes de matéria seca (DAMS), matéria orgânica (DAMO), proteína bruta (DAPB) e extrato etéreo (DAEE), função dos níveis de palma $(P)$ na dieta

Table 4 - Means, coefficients of variation (CV), fitted regression equation $(R E)$ and coefficient of determination $\left(R^{2}\right)$ of the coefficient of apparent digestibility of dry matter (ADDM), organic matter (ADOM), crude protein (ADCP) and ether extract $(A D E E)$, in the levels forage cactus $(P)$ in the diets

\begin{tabular}{|c|c|c|c|c|c|c|c|}
\hline \multirow[t]{2}{*}{ Item } & \multicolumn{4}{|c|}{$\begin{array}{l}\text { Níveis de palma forrageira }(\%) \\
\text { Levels of forage cactus }(\%)\end{array}$} & \multirow[t]{2}{*}{$\mathrm{CV}(\%)$} & \multirow[t]{2}{*}{$\mathrm{ER}(R E)$} & \multirow[t]{2}{*}{$\mathrm{R}^{2}$} \\
\hline & 0 & 12 & 24 & 36 & & & \\
\hline DAMS (ADDM) & 73,15 & 77,61 & 79,98 & 73,01 & 5,41 & $\mathrm{Y}=74,4847+0,578230 \mathrm{P}^{\mathrm{ns}}-0,016873 \mathrm{P}^{2^{* * *}}$ & 0,86 \\
\hline $\mathrm{DAMO}(A D M O)$ & 76,20 & 78,80 & 81,12 & 74,47 & 5,18 & $\mathrm{Y}=75,8286+0,558630 \mathrm{P}^{\mathrm{ns}}-0,016244 \mathrm{P}^{2^{* * *}}$ & 0,86 \\
\hline $\mathrm{DAPB}(A D C P)$ & 78,92 & 80,10 & 81,39 & 74,54 & 4,30 & $\mathrm{Y}=78,5190+0,403251 \mathrm{P}^{*}-0,013941 \mathrm{P}^{2 * *}$ & 0,87 \\
\hline $\operatorname{DAEE}(A D E E)$ & 66,40 & 73,80 & 71,90 & 66,76 & 10,64 & $\mathrm{Y}=66,7627+0,783736 \mathrm{P}^{\mathrm{ns}}-0,022049 \mathrm{P}^{2^{*}}$ & 0,96 \\
\hline
\end{tabular}

NS, * $e^{* *}$ não-significativo, significativo a $(P<0,05)$ a $(<0,01)$, respectivamente pelo teste $t$.

$N S,{ }^{*}$ and ${ }^{*}$ not significant, significant at $(p<.05)$ and $(P<.01)$ respectively, by $t$ test.

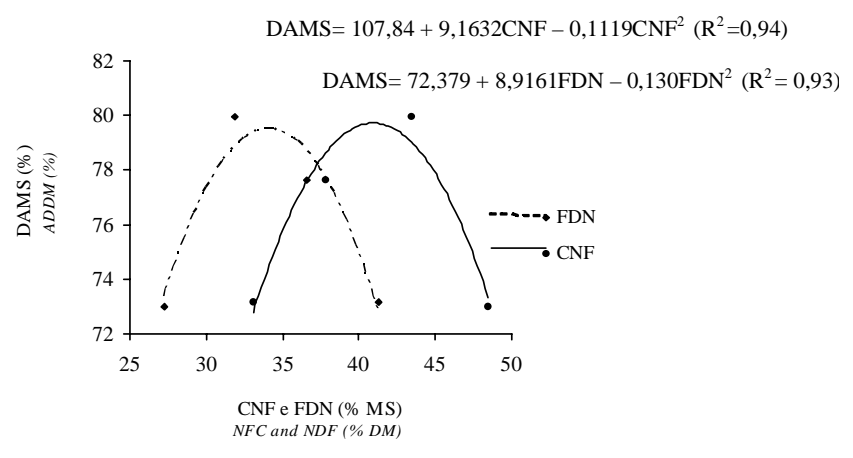

Figura 1 - Relação entre digestibilidade aparente de matéria seca (DAMS), teores de carboidratos não-fibrosos (CNF) e teores de fibra em detergente neutro (FDN).

Figure 1 - Relation between apparent digestibility of dry matter (ADDM), content of nonfiber carbohydrates (NFC) and content neutral detergent fiber (NDF).

FDN das dietas apresentou comportamento quadrático (Figura 1). Derivando-se as equações, foi possível estimar os valores máximos da DAMS (79,73 e $80,50 \%$ ), para os níveis de 40,94 e 34,29\% de CNF e FDN na dieta, respectivamente.

A digestibilidade da MS com a inclusão de palma às dietas apresentou comportamento similar ao que poderia ocorrer com a presença de altos níveis de concentrado. Dietas contendo tais alimentos apresentaram elevadas frações de CNF e/ou CNE, à medida que os teores de FDN diminuíram. Estes dados, em parte, explicam a diminuição na digestibilidade, a partir de determinado nível desses compostos, visto que ambos CNF e CNE, por serem prontamente fermentáveis, quando em quantidades elevadas, comprometem a atividade microbiana, prin- cipalmente das bactérias fibrolíticas, e, assim, a digestão (Véras et al., 2000).

O NRC (2001), com base na contribuição da FDN oriunda de volumosos, quando da formulação de dietas completas para vacas em lactação, recomenda um mínimo de $29 \%$ de FDN, com máximo de $40 \%$ de CNF dietéticos, de modo que pelo menos 17\% da FDN deve ser oriunda de volumosos. A partir da máxima DAMS, em função do nível de palma na dieta (Tabela 5) e da composição em FDN e CNF dos ingredientes da dieta (Tabela 1), estimou-se o teor de FDN dietético de $34,56 \%$, que proporcionou a máxima digestibilidade da MS, sendo 25,96\% da FDN dietética oriunda da silagem de sorgo e apenas $4,48 \%$ oriunda da palma. Portanto, ao se utilizar palma forrageira na alimentação de vacas de leite, devem-se respeitar as relações entre os teores de CNF e FDN nas dietas.

A estimativa da máxima DAMO, DAPB e DAEE foi de 80,$63 ; 81,42$; e $73,72 \%$, para os níveis de inclusão de palma na dieta de 17,19; 14,46; e 17,77\%, respectivamente.

Pode-se observar na Tabela 5 que as equações de regressão ajustadas dos coeficientes de DAFDN, DAFDA, DACHT, DACNF e teor de NDT, expressos em $\%$, apresentaram comportamento quadrático, com o aumento dos níveis de palma na dieta.

As máximas DAFDN, DAFDA, DACHT e DACNF foram estimadas em 65,$67 ; 67,21 ; 80,14$; e $93,10 \%$, respectivamente, para os níveis de 8,88 ; 13,$17 ; 17,18$; e $20,25 \%$ de palma na dieta. O comportamento quadrático verificado para DAFDN, DAFDA e DACHT pode ser explicado pela presença excessiva de CNF na dieta, que possivelmente ocasionou efeito depressivo sobre a fermentação microbiana, 
Tabela 5 - Médias, coeficientes de variação (CV), equações de regressão ajustadas (ER) e coeficiente de determinação $\left(R^{2}\right)$ das digestibilidades aparentes de fibra em detergente neutro (DAFDN) e ácido (DAFDA), carboidratos totais (DACHT) e carboidratos não-fibrosos (DACNF) e teor de nutrientes digestíveis totais (NDT), em função dos níveis de palma $(P)$ na dieta

Table 5 - Means, coefficients of variation (CV), fitted regression equation $(E R)$ and coefficient of determination $\left(R^{2}\right)$ of apparent digestibility of neutral detergente fiber (ADNDF) and acidr (ADADF), total carbohydrates (ADTCH), nonfiber carbohydrates (ADNFC) and total digestible nutrients (TDN) in function levels forage cactus $(P)$ in the diets

\begin{tabular}{|c|c|c|c|c|c|c|c|}
\hline \multirow[t]{2}{*}{ Item } & \multicolumn{4}{|c|}{$\begin{array}{c}\text { Níveis de palma forrageira }(\%) \\
\text { Levels of forage cactus }(\%)\end{array}$} & \multirow[t]{2}{*}{$\mathrm{CV}(\%)$} & \multirow[t]{2}{*}{$\mathrm{ER}(R E)$} & \multirow[t]{2}{*}{$\mathrm{R}^{2}$} \\
\hline & 0 & 12 & 24 & 36 & & & \\
\hline DAFDN $(A D N D F)$ & 64,56 & 61,93 & 62,89 & 43,85 & 14,77 & $\mathrm{Y}=63,4141+0,508176 \mathrm{P}^{* *}-0,0286037 \mathrm{P}^{2 * *}$ & 0,91 \\
\hline DAFDA $(A D A D F)$ & 63,60 & 64,90 & 66,50 & 53,80 & 13,84 & $\mathrm{Y}=62,9165+0,652699 \mathrm{P}^{\mathrm{ns}}-0,0247616 \mathrm{P}^{2^{*}}$ & 0,89 \\
\hline DACHT $(A D T C H)$ & 75,60 & 78,70 & 81,09 & 74,64 & 5,25 & $\mathrm{Y}=75,2789+0,587318 \mathrm{P}^{\mathrm{ns}}-0,0165114 \mathrm{P}^{2 * *}$ & 0,87 \\
\hline $\operatorname{DACNF}(A D N F C)$ & 89,06 & 92,10 & 93,24 & 90,51 & 2,60 & $\mathrm{Y}=88,9719+0,408429 \mathrm{P}^{\mathrm{ns}}-0,0100810 \mathrm{P}^{2 * *}$ & 0,98 \\
\hline $\operatorname{NDT}(\%)(T D N)$ & 73,84 & 76,05 & 77,70 & 71,56 & 5,44 & $\mathrm{Y}=73,4828+0,478762 \mathrm{P}^{\mathrm{ns}}-0,0144999 \mathrm{P}^{2^{* *}}$ & 0,88 \\
\hline
\end{tabular}

NS, * $e^{* *}$ não-significativo, significativo $(P<0,05)$ e $(P<0,01)$, respectivamente, pelo teste t.

$N S,{ }^{*}$ and ${ }^{*}$ not significant, significant at $(p<.05)$ and $(P<.01)$ respectively, by $t$ test.

diminuindo a atividade celulolítica pelo abaixamento do $\mathrm{pH}$ ruminal, conforme observado por Hall (2000), Pereira \& Armentano (2000) e Resende et al. (2001), e/ou aumento na taxa de passagem (Ørskov, 2000). O comportamento verificado para DACNF parece estar mais relacionado à taxa de passagem. O máximo teor de NDT foi estimado em 77,43\% para o nível de $16,51 \%$ de palma na dieta.

A relação entre a digestibilidade aparente de FDN e CNF da dieta apresenta-se descrita matematicamente por uma equação quadrática, sendo a digestibilidade máxima estimada em 65,69 com $37,08 \%$ de CNF na dieta (Figura 2).

De acordo com Van Soest et al. (1991), Allen (1997) e Allen \& Grant (2000), o tipo e a quantidade de carboidratos presentes no alimento afetam a fermentação e a eficiência microbiana. Nesse sentido, visto que a palma é rica nestes compostos, fazem-se necessários estudos de qualificação desses carboidratos, pois este grupo compreende açúcares e amido (carboidratos não-estruturais), frutanas, beta glucanos e pectina (fibra solúvel em detergente neutro) e ácidos orgânicos, que, de acordo com a quantidade e o arranjo no alimento, pode resultar em diferentes padrões de fermentação ruminal (Hall, 2001).

Ben Salem et al. (1996), trabalhando com palma na dieta de cordeiros em substituição à palhada de trigo, não observaram efeito dos níveis de palma sobre o pH ruminal, mas observaram redução na relação acetato:propionato e aumento na concentração de butirato. Silva et al. (1997) também encontraram maior concentração de propionato no rúmen de ovinos alimentados com dietas contendo palma

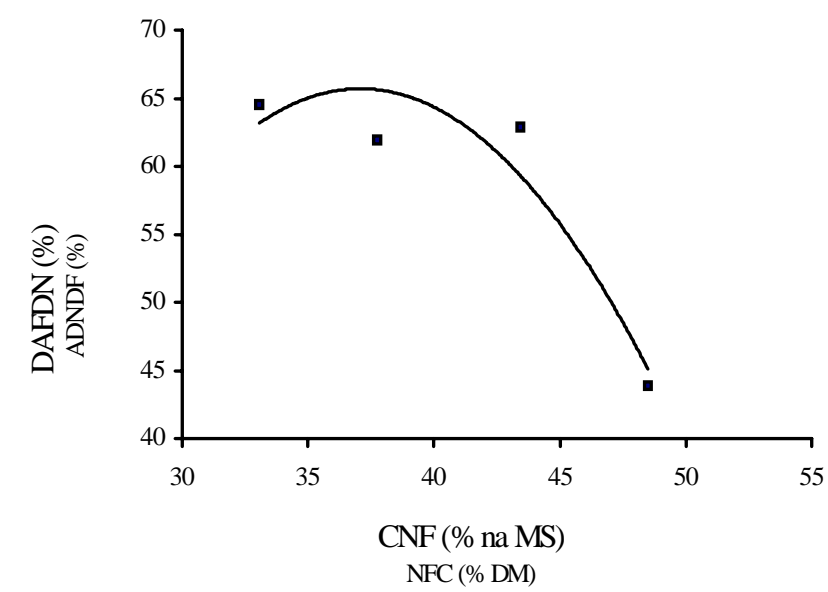

Figura 2 - Relação entre coeficiente de digestibilidade aparente de FDN (DAFDN) e teor de CNF da dieta.

Figure 2 - Relation between apparent digestibility of neutral detergent fiber (ADNDF) and content of nonfiber carbohydrates (NFC), in the diets.

forrageira e, conseqüentemente, menor relação acetato:propionato, verificando-se que a palma forrageira, como ingrediente da dieta, atua de forma semelhante a alimentos concentrados.

Mertens (2001) chamou a atenção para a necessidade de um suprimento adequado de fibra fisicamente efetiva, devendo a dieta conter um mínimo de $21 \%$, para vacas com produções acima de $30 \mathrm{~kg}$ leite/dia, estimulando a atividade mastigatória e aumentando o fluido salivar, rico em tamponantes, para manter o ambiente ruminal em condições normais, favorecendo a digestão dos nutrientes e a produção de gordura do leite.

Na Tabela 6 encontram-se as médias, os coeficien-

R. Bras. Zootec., v.31, n.5, p.2088-2097, 2002 
Tabela 6 - Médias, coeficientes de variação (CV), equações de regressão ajustadas (ER) e coeficiente de determinação $\left(r^{2} / R^{2}\right)$ dos coeficientes de absorção aparente de cálcio $(\mathrm{Ca})$, fósforo $(\mathrm{P})$, potássio $(\mathrm{K})$ e sódio $(\mathrm{Na})$, em função dos níveis de palma $(P)$ na dieta

Table 6 - Means, coefficients of variation (CV), fitted regression equation (RE) and coefficient of regression $\left(r^{2} / R^{2}\right)$ of the apparent absorption of calcium ( $\mathrm{Ca}$ ), phosphorous $(P)$, potassium $(K)$ and sodium $(\mathrm{Na})$, as function the forage cactus levels $(P)$ in the diets

\begin{tabular}{|c|c|c|c|c|c|c|c|}
\hline \multirow[t]{2}{*}{ Item } & \multicolumn{4}{|c|}{$\begin{array}{l}\text { Níveis de palma forrageira }(\%) \\
\text { Levels of forage cactus }(\%)\end{array}$} & \multirow[t]{2}{*}{$\mathrm{CV}(\%)$} & \multirow[t]{2}{*}{$\mathrm{ER}(R E)$} & \multirow[t]{2}{*}{$\mathrm{R}^{2}$} \\
\hline & 0 & 12 & 24 & 36 & & & \\
\hline $\mathrm{Ca}$ & 55,66 & 61,01 & 68,85 & 58,27 & 18,51 & $Y=52,6454+1,154700 p^{\text {ns }}-0,0273279 p^{2 *}$ & 0,94 \\
\hline $\mathrm{P}$ & 54,56 & 61,63 & 71,25 & 50,97 & 17,19 & $\mathrm{Y}=50,5729+1,90686 \mathrm{P}^{\mathrm{ns}}-0,0515214 \mathrm{P}^{2^{* *}}$ & 0,84 \\
\hline $\mathrm{K}$ & 87,01 & 91,97 & 94,02 & 94,74 & 4,20 & $\mathrm{Y}=87,2184+0,239180 \mathrm{P} * *$ & 0,85 \\
\hline $\mathrm{Na}$ & 45,07 & 76,10 & 81,07 & 82,80 & 13,11 & $\mathrm{Y}=46,7101+2,78392 \mathrm{P}^{\mathrm{ns}}-0,05030400 \mathrm{P}^{2^{* *}}$ & 0,97 \\
\hline
\end{tabular}

NS, ${ }^{*} e^{* *}$ não significativo, significativo $(P<0,05)$ a $(<0,01)$, respectivamente pelo teste $t$.

$N S,{ }^{*}$ and ${ }^{*}$ not significant, significant at $(p<.05)$ and $(P<.01)$ respectively, by $t$ test.

tes de variação, as equações de regressão e os coeficientes de determinação $\left(\mathrm{r}^{2} / \mathrm{R}^{2}\right)$ da absorção aparente de cálcio $(\mathrm{Ca})$, fósforo $(\mathrm{P})$, potássio $(\mathrm{K})$ e sódio $(\mathrm{Na})$, em função dos níveis de palma na dieta.

Os coeficientes de absorção aparente de $\mathrm{Ca}, \mathrm{P}$ e $\mathrm{Na}$ apresentaram comportamento quadrático e de K, comportamento linear crescente, em função dos níveis de palma nas dietas experimentais. As absorções aparentes para Ca e P foram 63,42 e 68,21\% para os níveis de 28,30 e 18,50\% de palma na dieta. Os efeitos quadráticos da absorção de $\mathrm{Ca}$ e $\mathrm{P}$, possivelmente, se devem ao fato de que, com a inclusão de palma às dietas, o consumo de $\mathrm{P}$ foi reduzido, ao passo que o de Ca aumentou (Wanderley et al., 2002), por sua maior participação nessa forrageira (Tabela 3 ).

Segundo Coelho da Silva (1995), a quantidade de Ca e $\mathrm{P}$ absorvida no trato digestivo é função da disponibilidade destes elementos no alimento, dos requerimentos e quantidades ingeridas pelo animal e da relação Ca:P. À medida que o Ca dietético aumenta acima dos requerimentos do animal, a absorção de ambos os elementos é reduzida, visto que esses nutrientes inorgânicos estão intimamente relacionados.

Wu et al. (2000) obtiveram valores médios de 46,25; 41,26; e 41,35\% de absorção aparente de P para diferentes níveis desse elemento $(0,31 ; 0,40$; e $0,49 \%$ ) na dieta de vacas holandesas em lactação. Araújo et al. (1994), trabalhando com vacas em lactação, alimentadas com dietas contendo diferentes níveis de proteína bruta degradada no rúmen, observaram valores médios de absorção aparente para Ca e P inferiores (36,2 e 43,6\%, respectivamente) aos encontrados neste trabalho. Véras et al. (2000), trabalhando com níveis crescentes de concentrado na dieta de bovinos nelore não-castrados, encontrou comportamento semelhante aos relatados no presente trabalho, com máximos de 65,72; 47,50; e 59,68\%, respectivamente, para absorções aparentes de $\mathrm{Ca}, \mathrm{P}$ e Na. De acordo com Mello \& Marques (1991), um meio ácido favorece a absorção de $\mathrm{Ca}$ e $\mathrm{P}$ pela formação de fosfato ácido de cálcio, prontamente solúvel e absorvível, sendo provavelmente, dietas ricas em carboidratos solúveis, em determinados limites, favoráveis a absorção desses elementos.

A relação Ca:P de 1,9:1 foi a que proporcionou os melhores coeficientes de absorção aparente 66,30 e $67,58 \%$, para ambos os elementos inorgânicos, respectivamente (Figura 3).

Salviano (1996) descreveu um compartimento quadrático para a absorção verdadeira de $\mathrm{P}$, utilizando níveis crescentes de $\mathrm{Ca}$ em dietas de ovinos, bem como variando a razão Ca:P, concluindo que a relação que proporcionou melhor absorção foi de 1,5:1,0. De acordo com Wu et al. (2000), o aumento no consumo de Ca pode limitar absorção do $\mathrm{P}$, por saturação ou inibição do mecanismo de absorção.

A análise de regressão permite descrever um comportamento linear positivo para o coeficiente de absorção aparente de $\mathrm{K}$, cujo valor médio foi de 91,93\%, superior aos 79,2\% relatados por Araújo et al. (1994) e aos 85\% descritos pelo NRC (2001) para forragens. Em publicações clássicas como ARC (1980), NRC (1989) e NRC (2001), o coeficiente de absorção verdadeira desse elemento é de $90 \%$. Apesar de o consumo de $\mathrm{K}$ ter aumentado linearmente (Wanderley et al., 2002), não foi detectado efeito depressivo sobre a absorção aparente, corroborando a afirmativa de que a absorção deste elemento inorgânico não está associada ao consumo, semelhantemente ao $\mathrm{Ca}, \mathrm{P}$ e Na, e sim com os requerimentos pelo animal (NRC, 2001). 


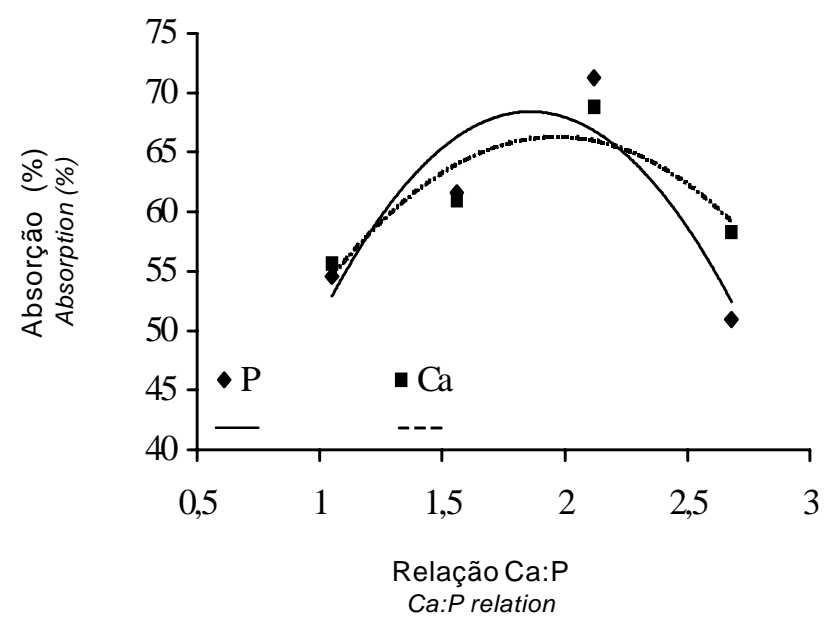

Figura 3 - Efeito da relação cálcio e fósforo (Ca:P), na absorção aparente de ambos os elementos minerais.

Figure 3 - Effect of relation between calcium and phosphorus (Ca:P), in apparent absorption of both minerals elements.

A máxima absorção aparente de $\mathrm{Na}$ foi de $83,3 \%$ para o nível de $26,2 \%$ de palma na dieta, sendo semelhante ao valor médio de $85 \%$ relatado pelo NRC (2001) para vacas leiteiras alimentadas com forragens frescas. Diante do exposto, sugerem-se mais estudos, envolvendo a adição de palma forrageira às dietas de vacas em lactação, pois esta apresenta altos teores de $\mathrm{CNF}, \mathrm{Ca}$ e $\mathrm{K}$ e baixos teores de $\mathrm{PB}$, FDN, FDA e P, interferindo diretamente sobre o coeficiente de digestibilidade aparente dos nutrientes. A inclusão de palma às dietas apresentou comportamento semelhante ao que poderia ocorrer com altos níveis de concentrado, devendo-se ter o máximo cuidado com a formulação de dietas principalmente quanto à relação volumoso:concentrado.

\section{Conclusões}

Para vacas em lactação, a digestibilidade de nutrientes de dietas à base de palma forrageira foi afetada pelos teores de carboidratos não-fibrosos (CNF) e fibra em detergente neutro (FDN).

Considerando os coeficientes de digestibilidade aparente de matéria seca (DAMS) e dos carboidratos totais (DACHT), bem como o teor de nutrientes digestíveis totais (NDT), o nível de inclusão da palma forrageira esteve limitado a $17 \%$ na dieta.

A relação Ca:P que proporcionou a melhor absorção desses elementos minerais foi de 1,9:1.

\section{Literatura Citada}

AGRICULTURAL AND FOOD RESEARCH COUNCIL AFRC. Technical commitee on responses to nutrients, Report 6. A reappraisal of the calcium and phosphorus requirements of sheep and cattle. Nutrition Abstract Reviews, v.61, n.9, p. 576-612, 1991.

AGRICULTURAL RESEARCH COUNCIL - ARC. The ruminant requirements of ruminant livestock. London: Commonwealth Agricultural Bureaux, 1980. 351p.

ALLEN, D.M.; GRANT, R.J. Interactions between forage and wet corn gluten feed as sources of fiber in diets for lactating dairy cows. Journal of Dairy Science, v.83, n.2, p. 322-331, 2000.

ALLEN, M.S. Relationship between fermentation acid production in the rumen and requirements for physically effective fiber. In: SYMPOSIUM: Meeting the fiber requirements of dairy cows. Journal of Dairy Science, v.80, n.7, p.1447-1462, 1997.

ARAÚJO, G.G.L.; COELHO DA SILVA, J.F.; VALADARES FILHO, S.C. et al. Absorção aparentes totais e parciais de cálcio, magnésio, fósforo e potássio pelas vacas lactantes. Revista Brasileira Zootecnia, v.23, n.5, p.773-781, 1994.

BEN SALEM, H.; NEFZAOUI, A.; ABDOULI, H. et al. Effect of increasing level of spinelles cactus ( Opuntia ficus indica var. inermes) on intake and digestion by sheep given strawbased diets. British Society Animal Science, v.62, n.1, p.293-299, 1996.

BERCHIELLI, T.T.; ANDRADE, P.; FURLAN, C.L. Avaliação de indicadores internos em ensaios de digestibilidade. Revista Brasileira de Zootecnia., v.29, n.3, p. 830-833, 2000.

BEZERRA NETO, E.; ANDRADE, A.G.; BARRETO, L.P. Análise química de tecidos e produtos vegetais. Recife: Universidade Federal Rural de Pernambuco 1994. 97p.

CARVALHO, A.U.; VALADARES FILHO, S.C.; COELHO DA SILVA, J.F. et al. Consumo e digestibilidade total dos nutrientes de dietas contendo diferentes níveis de concentrados em dietas de zebuínos. 1. Consumo e digestibilidade. Revista Brasileira de Zootecnia, v.26, n.5, p.986-995, 1997.

CARVALHO, F.F.R. Efeito de níveis de fósforo sobre digestibilidade, metabolismo, perda endógena e cinética de fósforo em cabritos Saanen. Jaboticabal: Universidade Estadual de São Paulo, 1998. 83p. Tese (Doutorado em Zootecnia) - Universidade Estadual de São Paulo, 1998.

COELHO DA SILVA, J.F. Exigências de macroelementos inorgânicos para bovinos: o sistema ARC/AFRC e a experiência no Brasil. In: SIMPÓSIO INTERNACIONAL SOBRE EXIGÊNCIAS NUTRICIONAIS DE RUMINANTES, 1995, Viçosa, MG. Anais...Viçosa, MG: Universidade Federal de Viçosa, 1995. p.467-503.

CUNHA, M.G.G. Efeito da adição de fibra em dietas a base de palma forrageira (Opuntia ficus indica Mill) sobre os parâmetros da fermentação ruminal e da digestibilidade em ovinos. Recife: Universidade Federal Rural de Pernambuco, 1996. 88p. Dissertação (Mestrado em Zootecnia) - Universidade Federal Rural de Pernambuco, 1996.

FARIAS, I.; FERNANDES, A.P.M.; LIMA, M.A. et al. Cultivo da palma forrageira em Pernambuco. Recife: Empresa Pernambucana de Pesquisa Agropecuária, 1984. 5p. (Documentos, 21).

GERMANO, R.H.; BARBOSA, H.P.; COSTA, R.G. et al. Avaliação da composição química e mineral de seis cactáceas do semi-árido paraibano. In: REUNIÃO DA SOCIEDADE BRASILEIRA DE ZOOTECNIA, 28., 1991, João Pessoa. Anais... 
João Pessoa: Sociedade Brasileira de Zootecnia, 1991. p.3.

HALL, M. B. Recentes avanços em carboidratos não-fibrosos na nutrição de vacas leiteiras. In: SIMPÓSIO INTERNACIONAL DE BOVINOCULTURA DE LEITE: Novos conceitos em nutrição, 2., 2001, Lavras. Anais... Lavras: Universidade Federal de Lavras, 2001. p.149-159.

HALL, M.B. Neutral detergent-soluble carbohydrates nutritional relevance and analysis. (s.l.): Institute of Food Agricultural Sciences and University of Florida, 2000. 41p. (Bolletin, 339).

LIMA, M.A.; FRANÇA, M.P.; DIAS, F.M. et al. Emprego da associação da palma forrageira e silagem de sorgo na alimentação de vacas holandesas em lactação. In: REUNIÃO ANUAL DA SOCIEDADE BRASILEIRA DE ZOOTECNIA, 22., 1985, Balneário Camboriú. Anais... Balneário Camboriú: Sociedade Brasileira de Zootecnia,1985. p.133.

MARTINS, A.S.; PRADO, I.N.; ZEOULA, L.M. et al. Digestibilidade aparente de dietas contendo milho ou casca de mandioca como fonte energética e farelo de algodão ou levedura como fonte protéica em novilhas. Revista Brasileira de Zootecnia, v.29, n.1, p.260-277, 2000.

MATTOS, L.M.E. Associação da palma forrageira (Opunti ficus indica Mill) com diferentes fontes de fibra na alimentação de vacas em lactação. Recife: Universidade Federal Rural de Pernambuco, 2000. 51p. Dissertação (Mestrado em Zootecnia) - Universidade Federal Rural de Pernambuco, 2000.

McDOWELL, R. L. Recentes avanços em minerais e vitaminas na nutrição de vacas em lactação. In: SIMPÓSIO INTERNACIONAL DE BOVINOCULTURA DE LEITE: Novos conceitos em nutrição, 2., 2001, Lavras. Anais... Lavras: Universidade Federal de Lavras, 2001. p.77-104.

McDOWELL, R.L. Feeding minerals to cattle on pasture. Animal Feed Science and Technology, v.60, p.247-271, 1996.

MELLO, M.A.; MARQUES, D.C. Deficiências minerais em ruminantes. Belo Horizonte: Universidade Federal de Minas Gerais, 1985. 46p.

MERTENS, D.R. Creating a system for meeting the fiber requirements of dairy cows. Journal of Dairy Science, v.80, n.7, p.1463-1481, 1997.

MERTENS, D.R. FDN fisicamente efetivo e seu uso na formulação de dietas para vacas leiteiras. In: SIMPÓSIO INTERNACIONAL DE BOVINOCULTURA DE LEITE: Novos conceitos em nutrição, 2., 2001, Lavras. Anais... Lavras: Universidade Federal de Lavras, 2001. p.38-49.

NATIONAL RESEARCH COUNCIL - NRC. Nutrients requirements of the dairy cattle. 6 .ed. Washington, D.C.: 1989. $158 \mathrm{p}$.

NATIONAL RESEARCH COUNCIL - NRC. Nutrients requirements of the dairy cattle. 7.ed. Washington, D.C.: 2001. 381p.

OLIVEIRA, F.R. Alternativas de alimentação para a pecuária no semi-árido nordestino. In: SIMPÓSIO NORDESTINO DE ALIMENTAÇÃO DE RUMINATES, 6., 1996, Natal. Anais... Natal: Simpósio Nacional de Produção Animal, 1996. p.127-147.

ØRSKOV, E.R. New concepts of feed evaluation for ruminants with emphasis on roughases and feed intake. Asian-Australasian Journal Animal Science, v.13, p.128-136, 2000.

PEREIRA, M.N.; ARMENTANO, L.E. Partial replacement of forage with nonforage fiber sources in lactating cows diets. II. Digestion and rumen function. Journal of Dairy Science, v.83, n.12, p.2876-2887, 2000.
RESENDE, F.D.; QUEIROZ, A.C.; OLIVEIRA, J.V. et al. Bovinos mestiços alimentados com diferentes proporções de volumoso:concentrado. 1. Digestibilidade aparente dos nutrientes, ganho de peso e conversão alimentar. Revista Brasileira Zootecnia, v.30, n.1, p.261-269, 2001.

RODRIGUES, M.T. Uso de fibras em dietas de ruminantes. In: CONGRESSO NACIONAL DOS ESTUDANTES DE ZOOTECNIA, 1998, Viçosa, MG. Anais... Viçosa, MG: Universidade Federal de Viçosa, 1998. p.141-169.

SALVIANO, L.M.C. Efeito de diferentes proporções de cálcio e fósforo sobre as perdas endógenas e absorção real de fósforo em ovinos. Piracicaba: Universidade de São Paulo, 1996. 83p. Tese (Doutorado em Zootecnia) - Universidade de São Paulo, 1996.

SANTANA, O.P.; ESTIMA, A.L.; FARIAS, I. Palma versus silagem na alimentação de vacas leiteiras. Revista Brasileira de Zootecnia, v.1, n.1, p.31-40, 1972.

SANTOS, D.C.; FARIAS, I.; LIRA, M.A et al. A palma forrageira (Opuntia ficus indica Mill Nopalia cochonillifera Salm Dyck) em Pernambuco: cultivo e utilização. Recife: Empresa Pernambucana de Pesquisa Agropecuária, 1997. 23p. (Documentos, 25)

SANTOS, D.C. Estimativas de parâmetros genéticos em caracteres de clones de palma forrageira, Opuntia ficus indica Mill e Nopalea cochenillifera Salm-Dyck. Recife: Universidade Federal Rural de Pernambuco, 1992. 119p. Dissertação (Mestrado de Zootecnia) - Universidade Federal Rural de Pernambuco, 1992.

SANTOS, M.V.F. Composição química, armazenamento e avaliação da palma forrageira (Opuntia ficus indica Mill e Nopalea cochenillifera Salm-Dyck) na produção de leite, em Pernambuco. Recife: Universidade Federal Rural de Pernambuco, 1989. 124p. Dissertação (Mestrado em Zootecnia) - Universidade Federal Rural de Pernambuco, 1989.

SANTOS, M.V.F.; LIRA, M.A.; FARIAS, I. et al. Estudo comparativo das cultivares de palma forrageira gigante, redonda (Opuntia ficus indica Mill) e miúda (Nopalia cochonillifera Salm Dyck) na produção de leite. Revista Brasileira de Zootecnia, v.19, n.6, p.504-511, 1990.

SCHMIDT, A.A.P. O sorgo. São Paulo: Icone, 1987. 63p.

SIGNORETTI, R.D.; COELHO DA SILVA, J.F.; VALADARES FILHO, S.C. et al. Consumo e digestibilidade aparente em bezerros da raça holandesa com dietas contendo diferentes níveis de volumoso. Revista Brasileira de Zootecnia, v.28, n.1, p.169-177, 1999.

SILVA, D.J. Análises de alimentos (métodos químicos e biológicos). Viçosa, MG: Universidade Federal de Viçosa, 1990. 165p.

SILVA, M.F.; BATISTA, A.M.; ALMEIDA, O.C. Efeito da adição de capim elefante a dietas a base de palma forrageira sobre a fermentação ruminal em bovinos. In: REUNIÃO ANUAL DA SOCIEDADE BRASILEIRA DE ZOOTECNIA, 34., 1997, Juiz de Fora. Anais... Juiz de Fora:Sociedade Brasileira de Zootecnia, 1997. p.140-142.

SNIFEEN, C. J.; O'CONNOR, J.D.; Van SOEST, P.J. et al. A net carbohydrate and protein system for evaluating cattle diets: II. Carbohydrate and protein availability. Journal of Animal Science, v.70, p.3562-3577, 1992.

UNIVERSIDADE FEDERAL DE VIÇOSA - UFV. SAEG Sistema de análises estatísticas e genéticas. Versão 7.1. Viçosa, MG. 1997. 105p. (Manual do usuário).

VALADARES FILHO, S.C. Nutrição, avaliação de alimentos e tabelas de composição de alimentos para bovinos. In: REUNIÃO ANUAL DA SOCIEDADE BRASILEIRA DE

R. Bras. Zootec., v.31, n.5, p.2088-2097, 2002 
ZOOTECNIA, 37., 2000, Viçosa, MG. Anais...Viçosa, MG: Sociedade Brasileira de Zootecnia, 2000. p.267-338.

VALADARES FILHO, S.C.; BRODERICK, G.A.; VALADARES, R.F.D. et al. Effect of replacing alfafa silage with high moisture corn on nutrient utilization and milk production. Journal of Dairy Science, v.83, n.1, p.106114, 2000.

Van SOEST, P.J. Nutritional ecology of the ruminant. 2.ed. Ithaca: Cornell University, 1994. 476p.

Van SOEST, P.J., ROBERTSON, J.B., LEWIS, B.A. Methods for extraction fiber, neutral detergent fiber and nonstarch polysaccarides in relation to animal nutrition. Journal of Dairy Science, v.74, n.10, p.3583-3597, 1991.

VÉRAS, A.S.C.; VALADARES FILHO, S.C.; SILVA, J.F.C. Consumo e digestibilidade aparente em bovinos Nelore, nãocastrados, alimentados com rações contendo diferentes níveis de concentrado. Revista Brasileira de Zootecnia, v.29, n.6(S), p.2367-2378, 2000.
WANDERLEY, W.L.; FERREIRA, M.A.; ANDRADE, D.K.B. et al. Palma forrageira (Opuntia ficus indica, Mipp) em substituição à silagem de sorgo (Sorghum bicolor (L.) na alimentação de vacas leiteiras. Revista Brasileira de Zootecnia, v.31, n.1, p.273-281, 2002.

WU, Z.; SATTER, L.D.; SOJO, R. Milk production, reproductive performance, and fecal excretion of phosphorus by dairy cows fed three amounts of phosphorus. Journal of Dairy Science, v.83, n.5, p.1042-1051, 2000.

Recebido em: 12/03/02

Aceito em: 30/08/02 